(2) Open Access Full Text Article

\title{
Presumed bilateral branch retinal vein occlusions secondary to antiepileptic agents
}

This article was published in the following Dove Press journal:

Clinical Ophthalmology

12 May 201 I

Number of times this article has been viewed

\section{Rumana N Hussain \\ Somnath Banerjee \\ Leicester Royal Infirmary, Leicester, UK}

Correspondence: Rumana N Hussain Leicester Royal Infirmary, Infirmary Square, Leicester LEI 5WW, UK Tel +44 (0)300 303 I573

Email rumanahussain@hotmail.com
Abstract: A 61-year-old man presented to the ophthalmology department having developed bilateral branch retinal vein occlusions. Baseline blood tests revealed no abnormality; however, subsequent investigations showed a raised plasma homocysteine (HC) level. The patient has been treated for refractory epilepsy for a number of years. Although antiepileptic medications have been shown to reduce folate levels and result in a raised HC level, this has not previously been shown to be to a level causing a retinal vascular event.

Keywords: homocysteine, branch vein occlusions

\section{Introduction}

Retinal vein occlusions are the second most common retinal vascular disease following diabetic retinopathy. A combination of hypertensive, atherosclerotic, inflammatory, or thrombophilic conditions may lead to retinal endothelial vascular damage. Hyperhomocysteinemia has been implicated as an independent risk factor for systemic vascular events, including retinal vascular disease. We present a case demonstrating the potential biochemical implications of antiepileptic agents and discuss their role in retinal vascular events.

\section{Case history}

A 61-year-old man was referred to the ophthalmology clinic by his optician for fundal changes noted at a routine eye examination. He was completely visually asymptomatic, with no past ocular history of note. His medical history included epilepsy, which had been difficult to control, for which he took phenytoin, topiramate, and pregabalin. There was no history of diabetes, hypertension, or cardiovascular disease, nor any family history of note. He smoked occasionally and drank little alcohol.

On examination, his visual acuity was 6/4 (20/13) in the right eye and 6/5 (20/15) in the left eye; anterior segment examination was normal with intraocular pressures within the normal range. Dilated fundal examination revealed right macular exudates and subretinal fluid, suggestive of a branch retinal vein occlusion (BRVO). In the left eye he demonstrated a few scattered retinal hemorrhages along the superotemporal arcade (Figure 1).

The patient's blood pressure was normal (117/70 mm Hg). He underwent a series of blood tests, revealing a normal full blood count, electrolytes, cholesterol, lipids and triglycerides, fasting glucose, autoantibodies, C3, C4, immunoglobulins, and thrombophilia screen. His only abnormality detected was a high serum homocysteine 


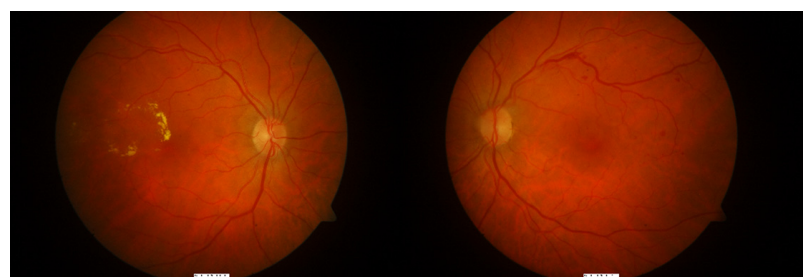

Figure I Color fundal photos demonstrating signs of branch vein occlusions in both left and right eyes.

(HC) level (20 umol/L). He was started on folate therapy, as this was considered the most likely cause of his raised HC level secondary to his antiepileptic medication but was subsequently discontinued as he noticed an increase in his seizure rate.

At his review appointment 2 months later, the patient reported a deterioration in the vision in his left eye; examination revealed a visual acuity of $6 / 24$ (20/80), extensive retinal hemorrhages along the superotemporal arcade, and diffuse macular edema. The visual acuity in the right eye remained satisfactory at 6/9 (20/30). His fluorescein angiogram revealed a right superotemporal BRVO with evidence of some macular edema and leakage; the left eye showed evidence of a superotemporal BRVO with extensive retinal hemorrhages and some late leakage around the macular region (Figure 2).

The patient underwent argon macular grid laser therapy to his left eye, which improved his acuity to 6/12 (20/40). He continues to be monitored.

\section{Discussion}

Antiepileptic drugs (AEDs) have been shown to be related to atherosclerosis and vascular risk. ${ }^{1}$ Even in children utilizing AEDs, cytochrome P450 liver enzyme-inducing agents such as carbamezapine, phenytoin, and phenobarbital have caused rises in cholesterol, triglycerides, and lowdensity lipoprotein levels. The effects may be reversible, as switching to alternative AEDs such as levetiracem or lamotrigine has been shown to correct such biochemical abnormalities. $^{2}$
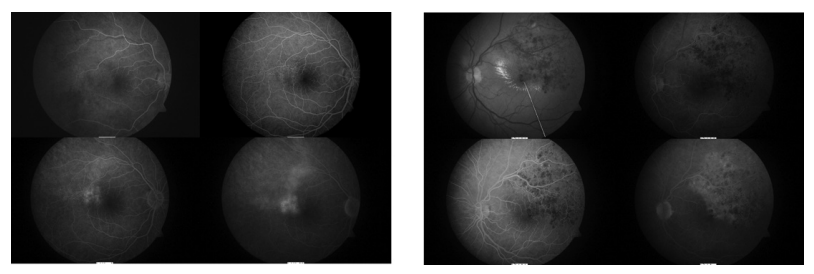

Figure 2 Fluorescein angiograms demonstrating bilateral branch vein occlusions with left macular edema.
The role of plasma HC has been suggested. The use of AEDs such as carbamezapine and sodium valproate have been shown to cause an increase in plasma HC levels, ${ }^{3}$ most likely due to disruption of folate metabolism. HC itself is well known to be an independent risk factor for vascular events. ${ }^{4}$ The mechanism of action remains uncertain, but suggestions include oxidative damage of endothelial cells, dysregulation of endothelial function due to endothelial nitric oxide synthase impairment, promotion of endothelial thrombotic functions such as platelet activation, and inflammatory processes. ${ }^{1}$ The relationship between $\mathrm{HC}$ and retinal vascular occlusion has also been well documented, both for central retinal vein occlusions ${ }^{5-9}$ and for branch vein occlusions. ${ }^{10,11}$ Although the false-positive rate for raised serum $\mathrm{HC}$ is approximately $5 \%$, making the test unsuitable for screening purposes, the dose-dependent relationship between HC levels and risk of cardiovascular disease is a factor not to be taken lightly in individuals who have had a vascular event. ${ }^{12}$

Cardiovascular events, including retinal vascular diseases, have a multifactorial causality, combining both occlusive and inflammatory parameters. This case demonstrates a potential causal factor involved that is often overlooked. Although $\mathrm{HC}$ levels have been related to AEDs, and raised plasma $\mathrm{HC}$ has been linked to vascular events, this is the first report of bilateral branch vein occlusion in a patient utilizing such antiepileptic agents. The potential risks of these AEDs ought to be respected and remembered when considering the choice of agents in patients, both young and old, when managing their seizures.

\section{Disclosure}

The authors report no conflicts of interest in this work.

\section{References}

1. Jakubus T, Michalska-Jakubus M, Lukawski K, et al. Atherosclerotic risk among children taking antiepileptic drugs. Pharmacol Rep. 2009;61:411-423.

2. Mintzer S, Skidmore C, Abidin C, et al. Effects of antiepileptic drugs on lipids, homocysteine, and C-reactive protein. Ann Neurol. 2009;65:448-456.

3. Aslan K, Bozdemir H, Unsal C, Guvenc B. The effect of antiepileptic drugs on vitamin B12 metabolism. Int J Lab Hematol. 2007;30: 26-35.

4. Kaplan ED. Association between homocyst(e)ine levels and risk of vascular events. Drugs Today (Barc). 2003;39:175-192.

5. Narayanasamy A, Subramaniam B, Karunakaran C, et al. Hyperhomocysteinemia and low methionine stress are risk factors for central retinal venous occlusion in an Indian population. Invest Ophthalmol Vis Sci. 2007;48:1441-1446.

6. Marcucci R, Bertini L, Giusti B, et al. Thrombophilic risk factors in patients with central retinal vein occlusion. Thromb Haemost. 2001;86:772-776. 
7. Lahey M, Tunç M, Kearney J, et al. Laboratory evaluation of hypercoagulable states in patients with central retinal vein occlusion who are less than 56 years of age. Ophthalmology. 2002;109:126-131.

8. Moghimi S, Najmi Z, Faghihi H, et al. Hyperhomocysteinemia and central retinal vein occlusion in Iranian population. Int Ophthalmol. 2008;28:23-28.

9. Gao W, Wang Y, Zhang P, Wang H. Hyperhomocysteinemia and low plasma folate as risk factors for central retinal vein occlusion: a casecontrol study in a Chinese population. Graefes Arch Clin Exp Ophthalmol. 2006;244:1246-1249.
10. Salaun N, Delyfer M-N, Rougier M-B, Korobelnik J-F. Évaluation du bilan étiologique des occlusions veineuses rétiniennes du sujet âgé de moins de 60 ans. J Fr Ophtalmol. 2007;30:918-923.

11. Weger M, Stanger O, Deutschmann H, et al. Hyperhomocyst(e)inemia, but not methylenetetrahydrofolate reductase C677T mutation, as a risk factor in branch retinal vein occlusion. Ophthalmology. 2002;109: $1105-1119$.

12. Wald DS, Law M, Morris JK. The dose-response relation between serum homocysteine and cardiovascular disease: implications for treatment and screening. Eur J Cardiovasc Prev Rehabil. 2004;11:250-253.
Clinical Ophthalmology

\section{Publish your work in this journal}

Clinical Ophthalmology is an international, peer-reviewed journal covering all subspecialties within ophthalmology. Key topics include: Optometry; Visual science; Pharmacology and drug therapy in eye diseases; Basic Sciences; Primary and Secondary eye care; Patien Safety and Quality of Care Improvements. This journal is indexed on

Submit your manuscript here: http://www.dovepress.com/clinical-ophthalmology-journal

\section{Dovepress}

PubMed Central and CAS, and is the official journal of The Society of Clinical Ophthalmology (SCO). The manuscript management system is completely online and includes a very quick and fair peer-review system, which is all easy to use. Visit http://www.dovepress.com/ testimonials.php to read real quotes from published authors. 